\title{
Trans-Attraction: Not Kink or Fetish, but a Legitimate Sexual Orientation*
}

\author{
Wendy Ashley, Randy Robertson \\ Social Work Department, California State University, Northridge, California, USA \\ Email: Wendy.Ashley@csun.edu, Randyallanrobertson@gmail.com
}

How to cite this paper: Ashley, W., \& Robertson, R. (2020). Trans-Attraction: Not Kink or Fetish, but a Legitimate Sexual Orientation. Open Journal of Social Sciences, 8, 212-227.

https://doi.org/10.4236/jss.2020.810014

Received: September 18, 2020

Accepted: October 24, 2020

Published: October 27, 2020

Copyright (อ 2020 by author(s) and Scientific Research Publishing Inc. This work is licensed under the Creative Commons Attribution International License (CC BY 4.0).

http://creativecommons.org/licenses/by/4.0/ (c) (i) Open Access

\begin{abstract}
Cisgender men who have sex with transgender women (MSTGW) are a relatively invisible population, known primarily through porn, erotica, kink, or diagnostic categorization. Labeled gyandromorphophilic, trans-amorous, trans-erotic and tranny chasers, the monikers used to describe the sexuality of MSTGW do not consistently encompass the nuances of orientation, attraction, identity and behavior of this population. Because they challenge conventional sexual orientation categories, MSTGW are often reduced to designation as subsets of existing binaries or variant type of sexuality, excluding them from the validation, support and connection that comes with community identification. In an effort to challenge the heteronormative, cisnormative and transphobic oppression inherent in MSTGW designation, the authors utilize the sex positive term trans-attraction. This article seeks to address the research question: What is the lived experience of a self-identified trans-attracted cisgender man? Using a qualitative auto-ethnographic approach, the authors describe and analyze a case study (Randy's story) to expose readers to the praxis of our collaborative autoethnography. The authors utilize reflexivity to contemplate a lived experience of trans-attraction, explore the limited binaries of sexual orientation, and consider trans-attraction as less of an urban phenomenon and more of a legitimate sexual orientation.
\end{abstract}

\section{Keywords}

Trans-Attraction, Kink, Fetish, Legitimate Sexual Orientation, Gyandromorphophilic, MSTGW

\section{Introduction}

"It is rare for an openly trans woman-no matter how 'passable' or attractive she is-to have a man who openly loves her, who has an unabashed de- 
sire to be seen with her, who proudly stands beside her-despite the stigma and other people's curiosities and inappropriate questions. Those questions regarding their sexuality are constant and fraught with assumptions, and for a man less secure it can be difficult navigating these questions. Until we begin checking how we delegitimize the identities, bodies and existence of trans women and stigmatize the men who yearn to be with us, we will continue to marginalize our ... men who don't have the space to explore, define and embrace their attraction to various women."

-Janet Mock

Cisgender men who have sex with transgender women (MSTGW) are a relatively obscure population, known primarily through exotic eroticism (Hsu, Rosenthal, Miller, \& Bailey, 2016), kink, fetishism, or paraphilias (Rosenthal, Hsu, \& Bailey, 2017). This population is labelled gyandromorphophilic (GAMP) by the medical and scholarly communities, and as transfan, trans catcher, trans erotic, transoriented, tranny chaser, tranny hawk, transamorous and transsensual by the kink, erotica and pornography communities. However, these labels are limiting and do not consistently incorporate the complexities of this population, minimizing and disregarding their nuances of orientation, attraction, identity and behavior. The authors identify this sexual orientation as trans-attraction, defining it as: physical and emotional attraction to a trans-identified person. Individuals within this population may identify as gay, bisexual, heterosexual, asexual, or other, but the narrow constriction of traditional sexual orientation binaries leaves minimal opportunities to translate lived experiences, attraction and partnership into a sexual orientation identity. Further, conventional sexual orientation categories are challenged by their unorthodox presentation, and those that identify as trans-attracted are often reduced to binaried designations that exclude them from community validation, support and connection. This article explores the vicissitudes of the medical and academic perspectives of cisgendered men who have sex with transgender women (including those identified as genderqueer, gender non-conforming and gender non-binary), trans relationships viewed as erotica or fetish, and lived experience. Using a case study as qualitative research, Randy's story will be used to examine a cisgender male's trans-attraction to transfeminine women, promote social justice for an invisible, marginalized population and validate its relevance as a legitimate sexual orientation. Case studies can be incredibly useful tools for integrating essential knowledge about the diverse backgrounds of invisible communities and clients into everyday interactions (Marsiglia \& Kulis, 2009; Noor, 2008).

\section{Trans-Attraction: Multiple Perspectives}

\subsection{Trans-Attraction Perspectives from the Medical and Scholarly Communities}

MSTGW are labelled gyandromorphophilic, or as GAMP's by the medical and 
scholarly communities, meaning they are attracted to gyandromorphs (GAMs), natal males with both breasts and a penis (Rosenthal, Hsu, \& Bailey, 2017). Because transgendered people are viewed with myriad of perspectives, the language used to identify trans individuals and their relationships varies widely. Scholarly literature reflects consistent pathological labeling of transgender women (male to female, or MTF), invisibility of transgender men (female to male, or FTM) and the complete absence of all other trans, queer, non-binary or gender non-conforming individuals. This invisibility is reflected in the terminology; the medical community refers to GAMs as men with breasts and a penis. There is no nomenclature for women with no breasts and a vagina (and/or a penis) or women following gender affirmation surgery. Additionally, there are many more names for transgendered women versus transgendered men. While many people use the terms transman and transwoman to identify transgendered persons, others refer to trans individuals as transsexuals, transwomen, t-girls or those with trans experience. Other, often offensive terms such as he-she, lady boy, chicks with dicks and she-male are also used, often highlighting the role of the real or imagined penis of the trans-identified person (Clark-Flory, 2011; Hsu, Rosenthal, Miller, \& Bailey, 2016).

Language can be used to label groups for classification or to devalue them. Language is particularly important when considering the role of power and control in how the trans community has been marginalized through oppression and discrimination (Tompkins, 2014). Often doctors, researchers and those with cisgender privilege justify their terminology, making statements such as "while it is reasonable for transgender women to object to being called male, they are still genetically male, which is the basis of the word male in "she-male" (Rosenthal, Hsu, \& Bailey, 2017: p. 256). Alternatively, Serano (2009) uses the terms transfeminine (to refer to those assigned male sex at birth but identify as women or are feminine in gender presentation or expression) or transmasculine (to refer to those assigned female sex at birth but identify as men or are masculine in gender presentation or expression) to allow for self-identification based on identity, preference and gender expression.

Language reflects power, especially when utilized by dominant groups. The terms MSTGW and GAMP are consistently utilized when referencing cisgendered men who have sex with trans women in academic or scholarly literature. There is no term for cisgendered women or cisgendered men who have sex with trans men. Outside of academia, trans-attracted men are frequently called tranny chasers, transfansor considered to have a fetish (Clary-Flory, 2011), eradicating the validity of the relationships and intimate connections with the transgendered population. Consistently, the focus of the language is on the gender identity of the trans partner and the sexual interactions between the two. Operario, Burton, Underhill and Sevelius (2008) note that sexual orientation identity terminology reflects gendered patterns of sexual attraction, but does not necessarily represent behavior or experience. Trans-attracted men self-identify as heterosexual, gay, bisexual, asexual or other. In prior research, GAMP men 
noted that they felt pressure to select an identity within the limiting binary (Coan, Shrager, \& Packer, 2005; Weinberg \& Williams, 2010). Because of stigma that simultaneously shames these men and pejoratively labels their relationship dynamics, they are often reduced to designation as subsets of existing binaries, variant or an unusual type of sexuality.

Contemporary sexual orientation terminology incorrectly assumes that binaried positions accurately capture the nuances of orientation, attraction, identity, lived experiences, partnerships and behavior included in romantic and sexual relations. Hsu and colleagues (2016) found that GAMP men were most likely to identify themselves as heterosexual or bisexual, concluding that GAMP men were much more similar to heterosexual rather than gay men in their arousal patterns. Despite these findings, Rosenthal, Hsu and Bailey (2017) stated that this group is "puzzling to scientists and themselves" (p. 261), and concluded that GAMP is best considered an unusual form of sexuality rather than a separate sexual orientation. Their premise is that only a minority of GAMP men have had sexual interest in transwomen beyond masturbatory fantasy; for the population to be a distinct sexual orientation, there would be larger percentage of participants with romantic or longer-term relationships with transwomen (Rosenthal, Hsu, \& Bailey, 2017). Outside of the flaws in generalizing findings from 314 participants to an entire population, this statement does not take into consideration the invisibility and lack of representation that come from marginalization. Further, researchers who describe this population as "challenging our conceptual understanding of sexual orientation" (p. 262) may not realize that their dominant, heteronormative lens may be reflected in their research, impacting the safety, comfort and honest responses of the participants (Rosenthal, Hsu, \& Bailey, 2017). Specifically, this can look like holding back or avoidance (Gamarel et al., 2014). External stressors such as discrimination, stereotypes and bias or internalizing negative messages from researchers about their relationship may create a stressful context, inhibiting communication and impacting the quality, accuracy and generalizability of the research findings.

\subsection{Trans-Attraction through the Lens of Sexually Evocative Material}

Erotica. Some of trans-attracted men's exclusion from serious consideration as a sexual orientation is the visibility and association of transgender relationships as erotic or pornographic. Multiple studies have been initiated utilizing erotic contexts to measure trans-attraction. Rosethal, Hsu and Bailey (2017) reported that PornHub had 33,971 video results for the search terms she-male, transvestite, cross-dresser and transwoman. Weinberg and Williams (2010) studied MSTGW via interviews at a bar, utilizing a commercial and/or casual sex setting as a context for the exploration of sexual attraction. Their findings contended that cisgendered men's sexual interest in transwomen is primarily about titillation, sexual release and easy sex (Weinberg \& Williams, 2010). While pornography and bars are viable settings to obtain data on this population, the con- 
texts themselves clearly influence the type of data researchers obtain. Viewing transgendered women through the lens of sexualization, erotica or pornography espouses their pervasive objectification. Physical and emotional attraction to a trans-identified person is considered taboo, and eroticizing trans individuals indicates it is acceptable to fuck, but not love trans women. Allen (2017) asserts that it is essential that we examine our aversion to transwomen as viable romantic options. Aversion and objectification promote stigma, positioning the men who are attracted to trans women as secretive and isolated.

Pornography. Trans-attraction may appear to those wedded to binaried sexuality as a product of erotica, pornography or kink, due in part to media's representation of transgender individuals. Mainstream media oversimplifies, sensationalizes or makes invisible transgender and genderqueer people's erotic identities, sex lives and fantasies. Allen (2017) describes media representation of transwomen as consistently negative, depicting them as serial killers, deceivers and men in dresses. Pornography traditionally caters to straight, cis men, and frequently involves the fetishization of transwomen's bodies, with characterizations such as chicks with dicks topping a cis man. "T-girl" porn has a primary audience of heterosexual men, and commonly features transwomen who haven't fully transitioned; they were born with male bodies, identify as female and have not had full sexual reassignment surgery (i.e. bottom surgery) (Clark-Flory, 2011). Porn has begun an evolution to include trans and gender variant performers, made by trans people and queer cis allies to be produced in a sex positive framework (Tompkins, 2014). This shift, while protracted, counteracts negative, pathologizing and exploitative depictions of trans sexualities and allows space for trans validating discourse. Trans porn and erotica produced in a sex positive framework can be affirming and can serve as a catalyst for new discourse and perspectives about trans experiences and sexualities.

Kink. "Kink" is a broad term that refers to a wide variety of consensual, non-traditional sexual, sensual, and intimate behaviors such as sadomasochism, domination and submission, erotic roleplaying, fetishism, and erotic forms of discipline. These sexualities involve intense sensations, sensual experiences associated with erotic targets and power differences (Sprott \& Hadcock, 2017). The terms sex positive or kink positive are defined as any sexual act outside of conventional or traditional sex. Kink identity isn't always associated with queer communities, but there are shared experiences, particularly in the area of safety and privacy. However, to define trans-attraction as kink defines trans identified individuals as erotic targets and/or sexual relationships with them as non-traditional behaviors. These definitions further objectify and invalidate trans relationships and sexual identities.

\subsection{Trans-Attraction via the DSM 5: Paraphilias and Fetishes}

Paraphilia and fetish are diagnostic classifications that are utilized to describe mental health disorders in the Diagnostic and Statistical Manual of Mental Disorders, Fifth Edition (DSM-5) (American Psychological Association, 2013). The 
DSM has a colorful history that consistently pathologizes sexuality, gender identity and sexually alternative acts. The term gyandromorphophilia contains the word philia, which, according to the DSM 5, is defined as a persistent, intense, atypical sexual arousal pattern (American Psychological Association, 2013). The DSM 5 makes a distinction between paraphilia and a paraphilic disorder, in that a paraphilia is the interest (erotic target) while paraphilic disorder involves engaging in the behavior (erotic activities) (American Psychological Association, 2013). However, to qualify as a disorder, there must be: personal distress regarding the interest, OR impairment in functioning, OR involve unwilling or nonconsenting partner(s). None of these are present in the majority of trans-attracted relationships.

Trans-attraction is often relegated to fetish or pathology. A fetish is any object or non-genital part of the body that causes a habitual erotic response or fixation (APA, 2013). Because trans-attraction challenges heteronormative and cisnormative ideology, trans-attraction within this framework is an abomination. This presumption is a trans-invalidation; assuming that trans people cannot be loved as whole people, but only as an object or fetish (Serano, 2009). Tompkins (2014) describes the difference between people that fetishize trans identified people with an erotic response because of transgender identity or genitalia and those who are uniquely attracted to trans individuals for reasons that go beyond intimacy. As a result, current language around trans-attraction is bifurcated into labels of "tranny chasing" or invisibility; trans-attracted individuals must accept pejorative labels or don't have words to describe their sexuality and are left without a sexual identity. The implications of this positionality are significant; trans-attracted individuals are pathologized and fetishized, their sexual orientation and sexuality is not affirmed, and the cis partner in the relationship is left without a way to discuss their sexuality as it relates to their trans or nonbinary partner (Tompkins, 2014).

\section{Research Methodology}

Autoethnography methodology is a continuum of ethnographic research approaches that seek to interpret, describe, explore, analyze and enhance phenomena in field research studies, similar to case studies (Anderson, 2006). However, this form of methodology ventures away from the traditional ethnographic research in that it maintains that transformation occurs through active engagement with the material, rather than from generating external discourse and broader contextual generalizations (Chang, 2008). The authors believe that this method provides more of a personal context and illuminates how Randy's story authentically expresses his lived experience and reflects our clinical therapeutic work from a multi-dimensional, intersectional perspective.

\section{Randy's Story: A Lived Experience of Trans-Attraction}

"When I say I identify as trans-attracted I don't mean that I have a fetish or I am the married man who hires a trans escort to fulfill some taboo fantasy. I hate the 
term "tranny-chaser." When I say trans-attracted I mean the physical, emotional, and spiritual attraction and connection with transgender or transsexual women. There is something that trans women have (no, not just a penis and breasts) that I love, a "trans spirit." I know there are politically correct ways of referring to trans women, and it is not my intention to disrespect them; I say trans, transgender and transsexual to refer to ALL women of trans experience.

I grew up thinking I was straight. I was always attracted to girls. I remember having a crush on a girl in kindergarten, and chasing her around the schoolyard at recess. In the summers I would stay at my dad's apartment after my parents divorced. He lived like a bachelor, with a sofa and dining chairs that were worn and shabby, donated to him by my mom. When he would go to work I would dive into his Playboy and Penthouse Magazine collection and get turned on to all those beautiful women. One summer while working at my dad's summer camp for people with developmental disabilities, I met a girl who was a junior camp counselor. I was very attracted to her and I had sex for the first time on the river beach.

In high school I was a big slut, adding another notch on my masculinity belt with each girl I slept with. I enjoyed it, but never had any lasting relationships. During that time, I began getting confused sexually because although I enjoyed having sex with girls, afterwards I kind of felt empty like there was something missing. At this time I had no idea about what trans even was, but started being attracted to very androgynous guys. This was in the 80's, and androgynous presentation was popular. I was particularly attracted to a guy that dressed androgynously and wore make-up. They called him "The Boy George" of Sonoma County and he had a following of young girls. I was introduced to him and one night he was in my car, and I remember feeling my heart was pounding and realized I was more excited than with any of the girls I had been with in the past. We kissed and it felt very satisfying. We began dating, but we never had sex because he had sexual abuse issues. One night I was walking in the park in the town square, and I ran into one of my old friends who asked "What's it with you being a homosexual? I heard you were dating a guy." Immediately a rush of shame flooded my body, and I came up with some lie that someone was spreading those rumors because he was dating a guy. He didn't believe me, from that point on, he stopped hanging out with me. I was confused because I didn't think I was gay because I wasn't attracted to men- at least not masculine men. The "Boy George-esque" relationship faded and I was back having sex with women.

I moved to San Francisco and went to many clubs and bars, where I was exposed to transgender women for the first time. Larkin street in San Francisco was where many trans prostitutes would work the streets. There were many guys who made it a point to drive around the block until they spotted the girl they wanted. The process was always the same: The girls would lean over through the pass side window, negotiate price, hop in their car and drive off. I was intrigued by this, so I started driving around the block too, looking at these beautiful women. There was also a bar at the corner of Larkin and Post called" The Moth- 
er Load." It was what everyone called a "Tranny Bar," and I would go on weekends and just watch the girls dance. This was my introduction to the transgender world. From then on, every time I would go to The City, I would drive by that street looking at all the beautiful women. I was attracted to these women in a way I had never experienced before.

I felt this is what I was missing. I never felt part of the LGBTIQQA community or felt gay, although I labeled myself that for a while because there was not yet a word for a man who was trans-attracted. I was in my first relationship with a transwoman for 3 years. A few years after that relationship ended I moved to Los Angeles and was in a relationship with a transwoman for 10 years. After she had her sexual reassignment surgery, we ended the relationship. One of the reasons is because of her becoming post-op. We tried having sex, but it felt weird and wrong to me.

My family and friends didn't deal with my sexuality well. It really hurt when my mom rejected me for my sexual orientation and later disowned me. I needed my mom as a parent and a source of support, and instead I got shamed. I felt hurt, scared and defective and like I was worthless and to be thrown away. I also felt shame with my friends in high school who found out that I was dating pretty boys and also rejected me. I was also rejected at work on the stock exchange when I came out. Someone called me a "faggot." Later when I was dating a transwoman, my mom asked, sarcastically "Is she a "real gir?" It was clearly something to be hidden, which over the years I have unfortunately internalized. I felt exposed and less than, not like a real man.

Work isn't a safe place either. Recently, I spoke to a colleague at work who attends the same gym as I do. He said he hasn't gone to the steam room or the pool because he wants to stay away from all the "homos." Although I don't identify as gay, I was offended by his comment. What would he think of $M E$ if he is offended by gay men?!?!? But despite my disgust, I caught myself trying to neutralize it, I kind of went along with it by saying," Well it wasn't as bad as before when the jacuzzi and steam room were in the men's locker room." It just makes me sad that people still have that attitude. And even sadder that I still struggle with managing people's comments. I keep telling myself "I am here to work, not make a political statement."

One of my core resources is a 12-step program, which is a consistent source of support. I use those meetings to share my ongoing struggles with shame, but even disclosing to a safe community can be scary and overwhelming for me. Recently, I went to a meeting planning to share, and I could feel my heart was beating in anticipation. When a woman I know walked in, I immediately got a little scared and thought "What if she was attracted to me?", and when I disclosed that I was attracted to transsexuals she might judge me. I talked myself down, and told myself this is the perfect opportunity to share it because of that. I watched as some men came in that were new to the meeting and I got scared again, fearing rejection. I waited until a few people shared and finally raised my hand to contribute. I was amazed it flowed out so easily. And fortunately, I was 
embraced by the 12-step community around me.

I have internalized the rejection I received from almost everyone around me. I have Obsessive Compulsive Disorder symptoms that mask this "core" issue. Questions like "Will I fit in?" or "What if they find out about my sexuality?" are constantly swirling around in my mind. I have a secret that no one can see or would imagine just by looking at me. I walk around work with significant shame, thinking "If my co-workers knew I was trans-attracted, they would reject me." I feel defective and flawed, which bleeds out from sexual orientation into feelings about me as a whole person. I realize love and self-acceptance start with myself. So I try to look in the mirror and say: "I love you Randy, and I accept your sexual orientation." And then I cry. Ultimately, the dark depression, sadness, and OCD cause their own shame. I have both an undefined sexuality and a mental Illness, and I feel flawed and broken.

I have been in therapy for a few years. I focus on my OCD, my feelings of shame and how I have internalized the rejection I received from family, friends and colleagues. One of the treatment goals we developed was to identify for myself a name for my sexuality. And I got really excited by that. Then my therapist asked if it would help to write an article about it so that other people who are like me might know they aren't alone. That was really meaningful to me.

I met a transwoman who is very attractive, has a successful career in the health industry and is very outgoing. She is an amazing woman with a professional career who is a role model for the transgender community, she shows that women of trans experience can be educated and have a professional career without having to work in the shadows. We got married five years ago. She does not want surgery because she, and we, are happy with her penis. Not all transwomen want surgery. We have had challenges as all relationships have. There have been some awkward times, like introducing her to my family. There was also the fear of what will my colleagues at work think when I bring her to the Christmas party. I got over my fears by facing them and trying not to care what others think. I love this woman and I am proud of our relationship.

I read that Native Americans have held transgender or androgynous people in high respect and regard. They referred to them as "two-spirit" people. They were commonly married to masculine men, or had sex with men, but were condemned by Spanish settlers. The Native Americans focused on a person's "spirit", or character, as being most important. I wish today's society could be as evolved."

\section{Discussion}

Randy's personal experience has remained largely unspoken prior to this article. Randy's story is used to critique practice, academic discourse and research that perpetuate heteronormative, transphobic assumptions about relationships, sexuality and identity. The themes indicated below, including shame, challenges and barriers to transparency in identity, and validation of a non-binaried sexual- 
ity reflect Randy's lived experiences as a trans-attracted, cisgender man. Through autoethnography, we hope to articulate one person's truth, while concurrently dismantling harmful stereotypes, ignorance and bias that maintain identity politics of silence and invisibility (Adams, Jones, Jones, \& Ellis, 2015).

\subsection{Shame}

One of the themes in Randy's story is his ongoing experience of shame as it relates to his sexuality. Trans-attraction questioning has led many well-known men to adamantly defend their heterosexuality and has tarnished the reputation and careers of others. Many men treat transgender women as inferior, and believe they should be honored by their attention (Moore, 2015). It sounds absurd, but often when gossip blogs are the public's only exposure to trans women, it spreads misinformation, validates stereotypes and causes irreparable damage. When a man can be shamed merely for interacting with a trans women, whether it be through a photograph, a sex tape or correspondences, the implications regarding trans women are substantial. This pervasive ideology says that trans women are shameful, that trans women are not worthy of being seen and that trans women must remain a secret, invisible and disposable. Additionally, this presumption is perplexing for the tran-attracted partner if they are viewed as normal while their partner is deemed invalid. Moore (2015) asserts that cisgender men hide their attraction to trans women to protect themselves from being labeled as gay and judged by society. If a man dares to be seen with a trans woman, he will likely lose social capital so he must adamantly deny, demean, or trash the woman in question to maintain his standing in our patriarchal society. Frost and Meyer (2009) suggest that both transgender individuals and their partners may internalize negative messages about trans people, causing relational conflict, isolation, and impacting both partners' psychological well-being.

There are a plethora of myths surrounding cisgender men who are sexually attracted to transgender women. One myth is that trans-attracted men are buffet oriented bisexuals; they enjoy sex with both men and women and delight in the opportunity for both at the same time. A common belief is that trans-attracted men are closeted gay men who are fearful of being outed, so they find solace in women who also have a penis (Notario, 2018). Hsu, Rosenthal, Miller and Bailey (2016) challenged that myth, developing a study to compare men's claimed sexual attraction with the results of a device that measured sexual arousal. Findings reflected the men's arousal patterns matched their declarations; in particular, men who claimed attraction to trans women showed high arousal when watching transgender women, moderate arousal with cisgender women and very low arousal when watching men have sex with men (Hsu, et al, 2016). Notaro (2018) asserts that the theory of trans-attracted men as repressed homosexuals is transphobic, acknowledging that this perspective imposes a binary system in which only cisgender men and women can provoke or feel arousal (p. 3). Cisgenderism or cissexism is another likely contributor to the fortitude of both the mythology and binary; the ideology that cisgender identities are normal delegi- 
timizes trans identities, expressions and experiences (Blair \& Hoskin, 2019).

\subsection{Challenges and Barriers to Transparency}

Our current trans misogynistic socio-political climate is one in which trans and non-binary populations face inordinate amounts of stigma, discrimination and violence. Transgender individuals face high rates of hate crimes, violence and assaults, especially during transitions when their gender presentation doesn't align with binaried expectations (Jauk, 2013). In 2019, advocates tracked at least 26 deaths of transgender or gender non-conforming people in the U.S. due to fatal violence, the majority of whom were Black transgender women (Human Rights Campaign, 2020). The National Transgender Discrimination Survey found that $78 \%$ of transgender or gender non-conforming adults reported direct mistreatment at work while 59\% reported forced sexual violence or rape (Clement-Nolle, Marx \& Katz, 2006; Grant, et al, 2011). Most of us are well aware of the danger to the trans population, but it is not often that we consider the challenges facing their partners, lovers and significant others. Randy's story illuminates the challenges of safely claiming trans identified partners. Blair and Hoskin (2019) refer to the psychological distress associated with being a partner of a trans person and from being presumed gay as "stigma by association" (p. 2077).

Stigma is a significant barrier facing trans-attracted individuals. In a You.Gov (2017) survey, 21\% of Americans reported thinking being transgender is a mental illness and $75 \%$ reported an unwillingness to date a transgender male, female or someone self -identifying as non-binary, gender non-conforming or genderqueer (Bame, 2017). The same study found that $25 \%$ of people wouldn't tell anyone if they had sex with a trans identified person (Bame, 2017). Tourjee (2015) contended that cultural stigma against loving transgender women is deeply ingrained in our society, to the point of ubiquity (p. 11). Those who are openly in relationships with trans-identified persons often feel compelled to answer questions about their identity, masculinity, femininity and sexuality. For many cis men, there is an ongoing internal conflict between their identity as a straight man and being seen as gay (Tourjee, 2015). Sexual behavior is also questioned. Engagement in sexual practices of topping (penetrating), bottoming (receptive to penetration), and the role and significance of the penis are used as indicators of sexual orientation (Mauk, Perry, \& Munoz-Laboy, 2013). The penis appears to maintain a central role in sexuality; as a result, transwomen's bodies are often polarized in their perception as a weapon or a sex toy.

Relationships with trans identified individuals have their own challenges. One of the challenges is in maintaining companionship and intimacy without the constraints of heterosexism and heteronormative expectations (Mauk, Perry, \& Munoz-Laboy, 2013). Appropriately, the trans-attracted partner is often concerned about their safety, and wonder if they can be openly romantic, affectionate or intimate. For trans partners, both disclosure and the correlated safety concerns are relevant because they can also become targets for violence and discrimination (Platt \& Bolland, 2018). This can result in withdrawal, isolation and 
hypervigilance with family, colleagues, friends, and in social events. Randy's story reflects this experience of social and emotional disconnection. Isolation and rejection of sexual and gender minority relationships deny the validation and support partners need to avoid internalizing negative and stigmatizing messages. Mauk, Perry and Munoz-Laboy (2013) describe the trans relationships as "existing in a no-man's land, void of examples of relationships that mirror and validate their experiences (p. 800)." Heteronormative and cisnormative assumptions promote the expectation that all people and relationships are heterosexual, cissexual and cisgendered (Blair \& Hoskin, 2019). These assumptions impact the presence, inclusion and acceptance of trans relationships. Maintaining emotional stability and relational intimacy while managing societal devaluing and delegitimization is challenging emotional labor and taxing to relationships (Evans \& Moore, 2015).

\subsection{Validation of Identity: A New Way to Look at Non-Binaried Sexuality}

Sexual orientation is a multidimensional construct that encompasses identity, behavior and attraction and directs sexual and romantic interests (Galupo, Henise, \& Mercer, 2016). Current methods of conceptualizing sexual orientation are flawed in their capacity to capture the fluidity, complexity and nuances of human sexuality. Traditional measures of sexual orientation fail to represent the range of sexual minority experience, in particular for transgender individuals (Galupo, et al, 2014). There is a need to reconceptualize transgender and other non-binary relationships and sexuality to decentralize traditional categories of gender and sex from cisgender, heteronormative assumptions. One progressive non-heteronormative orientation is queer identity; queer identity is intentionally deconstructionist, ambiguous and inclusive in that there are no assumptions about gender, biological sex, behaviors or attraction (Sprott \& Hadcock, 2017). However, while queer identity is a useful term to challenge sexual and gender norms, it minimizes the significance of the trans individual in trans-attracted relationships.

There are complex politics when someone claims attraction to a trans person, whether to an individual or a larger preference (Tompkins, 2014). Denying trans-attraction undermines an integral part of their identity, while openly acknowledging trans-attraction leaves one vulnerable to labelling or pathologizing (Tompkins, 2014). When one partner is trans identified, non-binary or gender non-conforming, the relationship must navigate external transphobia, cissexualism and heteronormative expectations. As a result, they are at increased risk for family and community ostracism, discrimination and violence (Giammattei, 2015). Connections to community are vital for mental health and wellness. Community connections provide socialization, support for coping with stigma and assistance in managing minority stress (Sprott \& Hadcock, 2017). The partners of those who are trans identified may feel as though their sexualities are silenced or denied and they have less access to resources and support, 
rendering them invisible. Namaste (2000) defines this as erasure, designating that culture and institutions create a context that renders trans sexuality and relationships impossible.

\section{Conclusion}

Case studies provide powerful tools for integrating essential knowledge about the cultural backgrounds of communities and clients into everyday interactions. Randy's qualitative auto-ethnography illuminates his cultural experience as a trans-attracted, cisgender man. There is a dearth of literature that explores the experiences of those who partner with trans identified individuals, with the majority of existing research on gender transition (of the trans partner) or sexual interaction (Blair \& Hoskin, 2019; Hsu, Rosenthal, Miller, \& Bailey, 2016; Rosenthal, Hsu, \& Bailey, 2017; Weinberg \& Williams, 2010). Because of the emphasis on the trans partner or the sexuality of the relationship, the partner experience is often overlooked. As a result, the partners of transgender individuals are often rejected, isolated and stigmatized by their families, communities and the LGBTQ community (Platt \& Bolland, 2018). Change often begins with authentic (and often difficult) discourse about lived experiences of invisible populations. A sex positive trans politics that celebrates diverse identities and sexual relationships can only develop in communities where there are open dialogues about trans bodies, desires, attraction and sexualities (Tompkins, 2014).

The medical term gynandromorphophilia evokes disease, or at the very least pathology. However, the term is offensive because it pathologizes trans-attracted men and because it invalidates the lived experiences of these men who love, have relationships and are sexually attracted to trans women. In order to capture the fluid experiences of those who are marginalized, oppressed and isolated by those constructs, it is critical to reconceptualize orientation beyond heteronormative, cisgender and cissexual binaries. Rejecting binary thinking often results in the creation of language that more accurately describes identities (Jourian, 2015). Tompkins (2014) asserts that there are currently no acceptable methods of discussing desire or attraction to trans identified individuals due to the taboos and fetishizing of the trans communities. The implications of this research are significant on micro and macro levels. Pathological characterization of sexuality and gender identity that contribute to heteronormative, cisnormative and transphobic oppression may be challenged, Randy's auto-ethnographic disclosures may provide validation for other trans-attracted individuals, and academics, researchers and mental health providers may benefit from increased understanding of an invisible population. Naming trans-attraction endorses a sex positive sexual orientation outside the binary that validates intimate romantic and sexual relationships with trans identified individuals.

\section{Acknowledgements}

We acknowledge the trans-attracted community. We see you and we honor you. 


\section{Conflicts of Interest}

The authors declare no conflicts of interest regarding the publication of this paper.

\section{References}

Adams, T. E., Jones, S. H., Jones, S. L. H., \& Ellis, C. (2015). Autoethnography. Understanding Qualitative Research. Oxford: Oxford University Press.

Allen, S. (2017). The Ridiculous Straight Panic over Dating a Transgender Person. The Daily Beast, 4 November 2017.

Anderson, L. (2006). Analytical Autoethnography. Journal of Contemporary Ethnography, 35, 373-395. https://doi.org/10.1177/0891241605280449

Bame, Y. (2017). 21\% of Americans Believe That Being Transgender Is a Mental Illness.. You.Gov. May 17, 2017.

https://today.yougov.com/topics/relationships/articles-reports/2017/05/17/21-america ns-believe-identifying-transgender-menta

Blair, K. L., \& Hoskin, R. A. (2019). Transgender Exclusion from the World of Dating: Patterns of Acceptance and Rejection of Hypothetical Trans Dating Partners as a Function of Sexual and Gender Identity. Journal of Social and Personal Relationships, 36, 2074-2095. https://doi.org/10.1177/0265407518779139

Chang, H. (2008). Autoethnography as Method. Walnut Creek, CA: Left Coast.

Clark-Flory, T. (2011). What's behind Transsexual Attraction? Salon.com, 21 October.

Clement-Nolle, K., Marx, R., \& Katz, M. (2006). Attempted Suicide among Transgender Persons: The Influence of Gender Based Discrimination and Victimization. Journal of Homosexuality, 51, 53-69. https://doi.org/10.1300/J082v51n03 04

Coan, D. L., Shrager, W., \& Packer, T. (2005). The Role of the Male Sexual Partners in HIV Infection among Male-to-Female Transgendered Individuals. International Journal of Transgenderism, 8, 21-30. https://doi.org/10.1300/J485v08n02 03

Evans, L., \& Moore, W. L. (2015). Impossible Burdens: White Institutions, Emotional Labor, and Micro-Resistance. Social Problems, 62, 439-454.

https://doi.org/10.1093/socpro/spv009

Frost, D. M., \& Meyer, I. H. (2009). Internalized Homophobia and Relationship Quality among Lesbians, Gay Men, and Bisexuals. Journal of Counseling Psychology, 56, 97-109. https://doi.org/10.1037/a0012844

Galupo, M. P., Davis, K. S., Grynkiewicz, A. L., \& Mitchell, R. C. (2014). Conceptualization of Sexual Orientation Identity among Sexual Minorities: Patterns across Sexual and Gender Identity. Journal of Bisexuality, 14, 433-456.

https://doi.org/10.1080/15299716.2014.933466

Galupo, M. P., Henise, S. B., \& Mercer, N. L. (2016). “The Labels Don’t Work Very Well”: Transgender Individuals' Conceptualizations of Sexual Orientation and Sexual Identity. International Journal of Transgenderism, 17, 93-104. https://doi.org/10.1080/15532739.2016.1189373

Gamarel, K. E., Reisner, S. L., Laurenceau, J. P., Nemoto, T., \& Operario, D. (2014). Gender Minority Stress, Mental Health, and Relationship Quality: A Dyadic Investigation of Transgender Women and Their Cisgender Male Partners. Journal of Family Psychology, 28, 437-447. https://doi.org/10.1037/a0037171

Giammattei, S. V. (2015). Beyond the Binary: Trans-Negotiations in Couple and Family Therapy. Family Process, 54, 418-434. https://doi.org/10.1111/famp.12167 
Grant, J. M., Mottet, L. A., Tanis, J., Harrison, J., Herman, J. L., \& Keisling, M. (2011). Injustice at Every Turn: A Report of the National Transgender Discrimination Survey. Washington DC: National Center for Transgender Equality and National Gay and Lesbian Task Force.

Hsu, K., Rosenthal, A., Miller, D., \& Bailey, J. (2016). Who Are Gynandromorphophilic Men? Characterizing Men with Sexual Interest in Transgender Women. Psychological Medicine, 46, 819-827. https://doi.org/10.1017/S0033291715002317

Human Rights Campaign (2020). Fatal Violence against the Transgender and Gender Non-Conforming Community in 2020.

https://www.hrc.org/resources/violence-against-the-trans-and-gender-non-conformin g-community-in-2020

Jauk, D. (2013). Gender Violence Revisited: Lessons from Violent Victimization of Transgender Identified Individuals. Sexualities, 16, 807-825.

https://doi.org/10.1177/1363460713497215

Jourian, T. J. (2015). Evolving Nature of Sexual Orientation and Gender Identity. New Directions for Student Services, 2015, 11-23. https://doi.org/10.1002/ss.20142

Marsiglia, F. F., \& Kulis, S. (2009). Diversity, Oppression, and Change: Culturally Grounded Social Work. Chicago, IL: Lyceum Books.

Mauk, D., Perry, A., \& Munoz-Laboy, M. (2013). Exploring the Desires and Sexual Culture of Men Who Have Sex with Male-to-Female Transgender Women. Archives of Sexual Behavior, 42, 793-803. https://doi.org/10.1007/s10508-013-0079-Z

Moore, L. (2015). Men Speak out about Being Attracted to Transgender Women. Cosmopolitan, 14 October 2015.

https://www.cosmopolitan.com/sex-love/news/a47721/men-speak-out-about-being-att racted-to-transgender-women/

Namaste, V. K. (2000). Invisible Lives: The Erasure of Transsexual and Transgendered People. Chicago, IL: University of Chicago Press.

Noor, K. B. M. (2008). Case Study: A Strategic Research Methodology. American Journal of Applied Sciences, 5, 1602-1604.

Notaro, P. C. (2018). Gyandromorphophilia: Who Are the Men Who Love Transwomen? Ilgrandecolibri: Essere LGBT nelmondo. 25 September 2018.

https://www.ilgrandecolibri.com/en/gynandromorphophilia-love-transwomen/

Operario, D., Burton, J., Underhill, K., \& Sevelius, J. (2008). Men Who Have Sex with Transgender Women: Challenges to Category-Based HIV Prevention. AIDS and Behavior, 12, 18-26. https://doi.org/10.1007/s10461-007-9303-y

Platt, L. F., \& Bolland, K. S. (2018). Relationship Partners of Transgender Individuals: A Qualitative Exploration. Journal of Social and Personal Relationships, 35, 1251-1272. https://doi.org/10.1177/0265407517709360

Rosenthal, A., Hsu, K., \& Bailey, J. (2017). Who Are Gynandromorphophilic Men? An Internet Survey of Men with Sexual Interest in Transgender Women. Archives of Sexual Behavior, 46, 255-264. https://doi.org/10.1007/s10508-016-0872-6

Sprott, R. A., \& Hadcock, B. B. (2017). Bisexuality, Pansexuality, Queer Identity and Kink Identity. Sexual and Relationship Therapy, 33, 214-232.

https://doi.org/10.1080/14681994.2017.1347616

Tompkins, A. B. (2014). “There's No Chasing Involved”: Cis/Trans Relationships, “Tranny Chasers," and the Future of a Sex-Positive Trans Politics. Journal of Homosexuality, 61, 766-780. https://doi.org/10.1080/00918369.2014.870448

Tourjee, D. (2015). The Straight Men Who Have Sex with Trans Women. 
https://www.vice.com/en us/article/kb4jw9/the-straight-men-who-have-sex-with-trans -women

Weinberg, M. S., \& Williams, C. J. (2010). Men Sexually Interested in Transwomen (MSTW): Gendered Embodiment and the Construction of Sexual Desire. Journal of Sex Research, 47, 374-383. https://doi.org/10.1080/00224490903050568 